\title{
Efficacy and safety of olopatadine hydrochloride $0.77 \%$ in patients with allergic conjunctivitis using a conjunctival allergen-challenge model
}

This article was published in the following Dove Press journal:

Clinical Ophthalmology

14 September 2015

Number of times this article has been viewed

\section{Gail Torkildsen' \\ Abhijit Narvekar ${ }^{2}$ \\ Mark Bergmann ${ }^{3}$}

'Andover Eye Associates, Andover, MA, ${ }^{2}$ Alcon Research Ltd, Fort Worth, TX, ${ }^{3}$ Apex Eye, Cincinnati, OH, USA
Correspondence: Gail Torkildsen Andover Eye Associates, I 38 Haverhill Street - Suite 104, Andover, MA 0I8I0, USA

Tel +l 9784750705

Fax + I 9784750008

Email mdlasik@comcast.net
Background: Symptom relief for the duration of 24 hours after treatment would benefit patients with allergic conjunctivitis.

Objective: To compare the safety and efficacy of olopatadine $0.77 \%$ with vehicle or olopatadine $0.2 \%$ in patients with allergic conjunctivitis in a conjunctival allergen-challenge clinical study.

Patients and methods: In this Phase III, multicenter, double-masked, parallel-group, randomized trial, patients with allergic conjunctivitis received olopatadine $0.77 \%$, its vehicle, or olopatadine $0.2 \%$, administered once at visits $3 \mathrm{~A}$ (day 0 ), $4 \mathrm{~A}$ (day $14 \pm 2$ ), and 5 (day $21+3$ ). Allergic conjunctivitis-associated sign and symptom assessments included ocular itching, conjunctival redness, total redness, chemosis, and tearing scores. Adverse events and ocular safety parameters were also assessed.

Results: A total of 202 qualifying patients were randomized. Olopatadine $0.77 \%$ was superior $(P<0.001)$ to vehicle for treatment of ocular itching at 3,5, and 7 minutes postchallenge at onset of action and 16- and 24-hour duration of action. Conjunctival redness mean scores were significantly lower for olopatadine $0.77 \%$ versus vehicle at all three post-conjunctival allergenchallenge time points: onset $(-1.52$ to $-1.48 ; P<0.001)$, 16 hours $(-1.50$ to $-1.38 ; P<0.01)$, and 24 hours $(-1.58$ to $-1.38 ; P<0.05)$. At 24 hours, olopatadine $0.77 \%$ was superior to olopatadine $0.2 \%$ at all three postchallenge time points for ocular itching $(P<0.05)$, conjunctival redness $(P<0.05)$, and total redness $(P<0.05)$. No clinically relevant differences in safety parameters or adverse events were observed between the treatment groups.

Conclusion: Olopatadine $0.77 \%$ is superior to both its vehicle and olopatadine $0.2 \%$ for the treatment of allergen-mediated ocular itching and conjunctival redness. Ocular itching symptom relief is maintained over 24 hours, supporting once-daily dosing and demonstrating a comparable safety profile to olopatadine $0.2 \%$.

Keywords: allergic conjunctivitis, allergic rhinoconjunctivitis, ocular inflammation, antihistamine, conjunctival allergen-challenge (CAC) model, high-concentration olopatadine

\section{Introduction}

Frequently associated with allergic rhinitis, allergic conjunctivitis is the most common form of ocular allergy, ${ }^{1,2}$ resulting in a condition better known as "allergic rhinoconjunctivitis". ${ }^{1,3}$ Itchy eyes and nasal congestion are the main symptoms, often accompanied by irritability and fatigue. ${ }^{1}$ Despite the efficacy of the current available products to treat allergic conjunctivitis, patients experiencing incomplete symptom relief are likely to benefit from using a product that provides symptom relief over the course of an entire day with the convenience of once-daily dosing.

Allergic conjunctivitis occurs when allergens such as grass or ragweed pollen, dust mites, and animal dander cause an immune reaction in the eye mediated by $\mathrm{IgE}$. 
A cascade of events leads to mast-cell degranulation and release of histamine and other proinflammatory mediators at the site of allergen invasion. ${ }^{4}$ The inflammatory reaction results in vasodilation, increased vascular permeability, leukocyte chemotaxis, and emigration of inflammatory cells into the surrounding tissue spaces, thus causing ocular inflammation, ocular itching, redness, tearing, swelling of the conjunctiva (chemosis), and eyelid swelling. ${ }^{4}$ Ocular symptoms in particular - itchy eyes, puffiness, and watering - can have a significant impact on patients' daily activities, leading to poorer quality of life and increased resource utilization, irrespective of the severity of nasal symptoms. ${ }^{5}$

The prevalence of allergic conjunctivitis is difficult to ascertain; however, $30 \%$ of the US population report nasal and ocular symptoms for at least 1 week of the year, and approximately $70 \%-80 \%$ of seasonal allergic patients have severe ocular symptoms. ${ }^{1}$ An estimated $14 \%$ of the US population are thought to suffer from allergic rhinoconjunctivitis, ${ }^{6}$ and $15 \%-20 \%$ of the Japanese population are thought to suffer from allergic conjunctival diseases. ${ }^{7}$

Available treatment options for the symptoms of allergic conjunctivitis include antihistamines, mast-cell stabilizers, or nonsteroidal anti-inflammatory drugs. ${ }^{8}$ Among antihistaminic drugs, olopatadine is a selective antagonist of histamine $\mathrm{H}_{1}$ receptors, causing mast-cell stabilization and prevention of histamine-induced inflammatory cytokine production. ${ }^{7,9}$ Olopatadine hydrochloride ophthalmic solutions at concentrations of $0.1 \%$ and $0.2 \%\left(\right.$ Patanol $^{\circledR}$ and Pataday ${ }^{\circledR}$, respectively; Alcon Research Ltd, Fort Worth, TX, USA) are effective for the management of allergic conjunctivitis, including reducing ocular itching. ${ }^{7,10-26}$

A new formulation of olopatadine hydrochloride ophthalmic solution was recently approved in the US by the Food and Drug Administration (FDA). Each milliliter of this new formulation contains $7.76 \mathrm{mg}$ of olopatadine hydrochloride, which is equivalent to $7 \mathrm{mg}$ olopatadine free base. As olopatadine is soluble only in water $(\mathrm{pH} \sim 7.0)$ at room temperature up to a concentration of $0.18 \% \mathrm{w} / \mathrm{v}$, the higher concentration olopatadine hydrochloride $0.77 \%$ formulation contains compounds to improve its solubility, including a cyclodextrin derivative (hydroxypropyl- $\gamma$-cyclodextrin), a lactam polymer (polyvinylpyrrolidone [povidone]), and polyethylene glycol (PEG400). ${ }^{27}$

Various methods can be used to assess the treatment effectiveness of antiallergy agents in subjects with allergic conjunctivitis, including environmental studies, in which patients are given a course of treatment to take at home where they record their symptoms throughout the study period. This type of study accurately reflects a normal clinical practice; however, confounding factors, such as variability in sensitivity to allergens, differing exposure to allergens, reliance on subjective data, and incomplete compliance, may make interpretation of the findings problematic. ${ }^{28} \mathrm{An}$ alternative methodology is based on a conjunctival allergenchallenge (CAC) model. ${ }^{29}$ The CAC allows a level of internal control that is not seen with environmental studies, has an inherent reproducibility of repeated study visits under controlled conditions, and has been used extensively for testing topical ophthalmic medications. ${ }^{28}$

This study compared the safety and efficacy of olopatadine $0.77 \%$ with its vehicle or olopatadine $0.2 \%$ in patients with allergic conjunctivitis, using a CAC model in a controlled setting. In order to assess the onset of action, as well as the duration of action at 16 and 24 hours postadministration, all tested therapies were administered as a single dose prior to each challenge on 3 nonconsecutive days.

\section{Patients and methods Study design}

This Phase III, multicenter, randomized, double-masked, parallel-group, vehicle- and active-controlled CAC trial was conducted under a common protocol at three investigational sites in the US. The study assessed the efficacy and safety of olopatadine $0.77 \%$ compared with its vehicle and olopatadine $0.2 \%$. One dose (one drop in each eye) of the assigned test article was administered 27 minutes, 16 , or 24 hours prior to a CAC test and allergic sign and symptom assessments. These dosing and CAC test visits occurred over a 3-week period after subject eligibility and randomization. Efficacy and safety were assessed using the CAC model (Ora-CAC ${ }^{\circledR}$; Ora Inc, Andover, MA, USA). ${ }^{29}$ In the CAC model, allergens are directly applied into the eye under controlled conditions to allow observations of acute allergic changes.$^{29}$ The $\mathrm{CAC}$ model includes a titration visit to determine the allergen and its dose that elicits a positive clinical response, and a confirmation visit to confirm the reproducibility of the response using the same allergen and dose that elicited the positive clinical response at the titration visit. The efficacy of the study drug is then tested at visits that comprise instillation of the study drug, followed by CAC and measurement of signs and symptoms of allergic conjunctivitis. $^{28,29}$

\section{Participants}

Male and female patients were eligible for inclusion if they were at least 18 years old, were able to have both eyes 
dosed with eyedrops, and had a positive diagnostic skin test indicative of allergy to cat hair, cat dander, grasses, ragweed, dust mite, dog dander, cockroaches, and/or trees within 24 months of visit 1 (day $21 \pm 2$, Figure 1). In addition, eligible patients were required to have a history of seasonal or perennial allergic conjunctivitis for $\geq 1$ year before visit 1 and a positive bilateral CAC response at visits 1 (day 21 \pm 2 ) and 2 (day 14 \pm 3 ), and were willing to discontinue wearing contact lens for $\geq 72$ hours before the first study visit and throughout the study.

Exclusion criteria included a known history or presence of persistent dry eye syndrome or recurrent treatment for dryness of eyes, and the presence of active blepharitis, active meibomian gland dysfunction, active rosacea affecting the ocular adnexa, follicular conjunctivitis, iritis, preauricular lymphadenopathy, ocular irritation not due to ocular allergy, or any other clinically significant ophthalmic abnormality. Other medical conditions that precluded participation in the study included presumed or actual ocular infection (bacterial, viral, or fungal) or a history of ocular herpes; the presence of any chronic ocular degenerative condition or active intraocular inflammation that in the opinion of the investigator was likely to worsen during the study; any contraindications or hypersensitivities to use of the study medications or their components; a history of ocular surgery (including refractive procedures, such as laser-assisted in situ keratomileusis, photorefractive keratectomy, and radial keratotomy, within 6 months; any type of glaucoma at visit 1; past history or diagnosis of glaucoma or glaucoma-suspect status (ocular hypertension); signs or symptoms of active allergic conjunctivitis; history of anaphylactic reaction to any study allergens; current evidence or recent (within 6 months) history of severe, unstable, or uncontrolled systemic disease; use of any disallowed medications during the period indicated prior to visit 1 in the protocol; any contraindications or hypersensitivities to use of the study medications or their components; or participation in another investigational agent trial within 30 days.

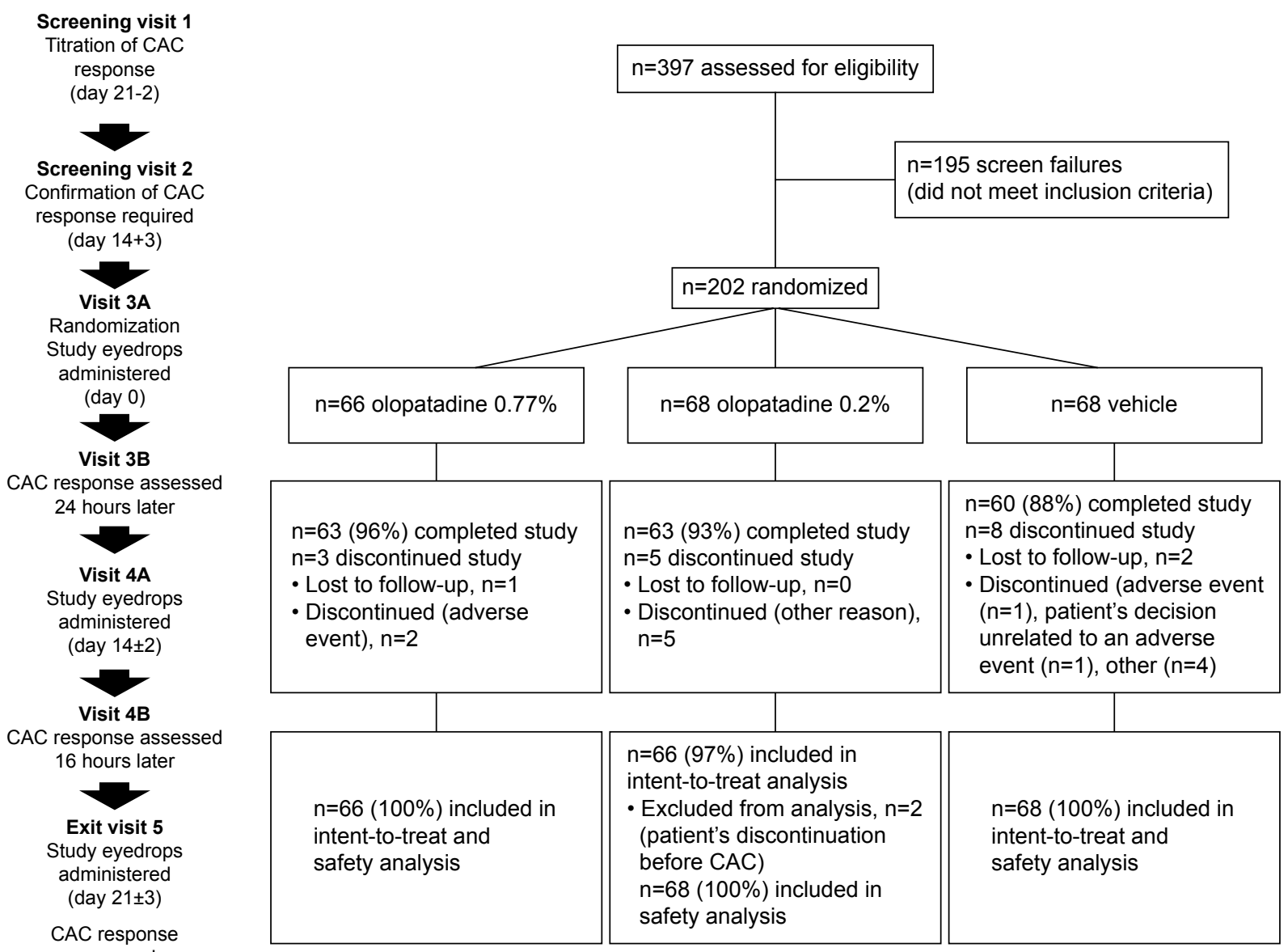

Figure I Study flow diagram.

Note: Olopatadine $0.77 \%$ refers to olopatadine $\mathrm{HCl} 0.77 \%$ (equivalent to olopatadine $0.7 \%$ free base)-treatment group.

Abbreviation: CAC, conjunctival allergen-challenge. 
The study was performed in compliance with the ethical principles of the Declaration of Helsinki and Good Clinical Practice guidelines, ${ }^{30}$ and all patients gave informed consent. The study protocol and informed consent form were reviewed and approved by all relevant independent Alpha Institutional Review Board. The trial was registered at ClinicalTrials.gov under the identifier NCT01479374.

\section{Study visits and treatment}

All patients were required to have a positive bilateral CAC response to the administered allergen, which was based on the individual's own allergic sensitivity, at visits 1 and 2 to be eligible for enrollment (Figure 1). At visit 1, a positive bilateral CAC response was defined as scores for each eye of $\geq 2$ itching and $\geq 2$ redness in two of the three vessel beds (ciliary, conjunctival, episcleral) within 10 minutes of the last titration challenge. At visit 2, a positive bilateral CAC response was defined as scores for each eye of $\geq 2$ itching and $\geq 2$ redness in two of three vessel beds for at least two of the three post-CAC time points.

Upon enrollment, eligible patients were randomized using an interactive response technology at visit 3A (day 0) to receive olopatadine hydrochloride $0.77 \%$, vehicle, or olopatadine hydrochloride $0.2 \%$ (ratio $1: 1: 1$ ). Patients received one dose of the assigned study medication at visits $3 \mathrm{~A}$ (day 0 ), $4 \mathrm{~A}$ (day $14 \pm 2$ ), and 5 (day $21+3$ ) prior to CAC at visits $3 \mathrm{~B}$ (24 hours after visit 3A), 4B (16 hours after visit 4A), and 5 (27 minutes after treatment instillation). A dose was defined as one drop per eye of the study product administered topically to each eye. All study medications were administered by designated site staff members, who were masked with regard to treatment assignment, along with all investigators and patients for the duration of the study.

\section{Study objectives and outcome measures}

The primary objective was to demonstrate the superiority of olopatadine $0.77 \%$ compared with its vehicle for the treatment of ocular itching associated with allergic conjunctivitis using the CAC immediately after dosing for onset of action and 16 hours after dosing to determine the duration of action.

Secondary objectives were to demonstrate the superiority of olopatadine $0.77 \%$ compared with its vehicle for the treatment of conjunctival redness following a CAC immediately after dosing for onset of action and 16 hours after dosing (16-hour duration of action). Superiority of olopatadine $0.77 \%$ compared with olopatadine $0.2 \%$ was also assessed for the treatment of total redness, ocular itching, and conjunctival redness following a CAC 24 hours after dosing.
Chemosis and tearing scores at the postchallenge time points were assessed for onset of action and 16 and 24 hours after dosing for duration of action.

\section{Efficacy variables}

Patients were asked to evaluate on a scale from 0 to 4 (using Ora proprietary scales $)$ ocular itching $(0=$ none, $4=$ incapacitating itch, 0.5 -unit increments) and tearing $(0=$ none, $4=$ very severe, 1 -unit increments). The investigator evaluated ciliary, conjunctival, and episcleral redness (each on a $0-4$ scale by 0.5 -unit increments; $0=$ none, $4=$ extremely severe), and chemosis $(0=$ none, $4=$ severe, 0.5 -unit increments).

Pre-CAC assessments of all mentioned ocular allergic signs and symptoms were conducted before dosing at visits $3 \mathrm{~A}, 4 \mathrm{~A}$, and 5. Ocular itching was assessed at 3, 5, and 7 minutes post-CAC at visits $3 \mathrm{~B}$ ( 24 hours after visit $3 \mathrm{~A}$ ), 4B (16 hours after visit 4A), and 5. Conjunctival, ciliary, and episcleral redness, chemosis, and tearing assessments were conducted at 7, 15, and 20 minutes post-CAC at visits $3 \mathrm{~B}, 4 \mathrm{~B}$, and 5 . Total redness score, ranging from 0 to 12 , was the sum of conjunctival, ciliary, and episcleral redness scores.

\section{Safety variables}

The safety of olopatadine $0.77 \%$ was assessed on the basis of the following parameters: best-corrected visual acuity, slit-lamp examination, intraocular pressure, dilated fundus examination, and all treatment-emergent adverse events (AEs).

\section{Statistical analysis}

All randomized patients who received study medication or had potential exposure were included in the safety population. The intent-to-treat population included all randomized patients who received at least one administration of study drug. Pair-wise treatment comparisons at each postchallenge time point were based on the mean derived from a statistical model for repeated measures. The model included fixedeffect terms for investigator, treatment, time, and treatmentby-time interaction. A separate model was used for each CAC (at visits 3B, 4B, and 5). Superiority of olopatadine $0.77 \%$ compared with vehicle was demonstrated if at least two of the three post-CAC time points were in favor of olopatadine $0.77 \%$ at the $5 \%$ level of significance (two-sided) for the onset-of-action and 16-hour duration-of-action primary comparisons on ocular itching.

The secondary hypotheses were tested in the sequence in which they were listed using a fixed-sequence testing 
multiplicity strategy to ensure correct interpretation of the results (without falsely asserting superiority of olopatadine $0.77 \%$ due to the high number of end points being tested). Each secondary hypothesis was evaluated for significance only if all preceding hypotheses (primary and secondary) were statistically significant in at least two of the three postCAC time points in support of olopatadine $0.77 \%$.

For olopatadine $0.77 \%$-versus-vehicle comparisons, a sample size of approximately 64 patients per treatment group was calculated to have a $99 \%$ power to detect, at a single time point, a mean difference of 1 unit, assuming that the common standard deviation was 1.0 for ocular itching using a twogroup $t$-test with a $5 \%$ level of significance (two-sided). The probability of rejecting the null hypothesis for at least two of the three time points was greater than $97 \%$ (based on the Bonferroni inequality). For olopatadine $0.77 \%$-versus- $0.2 \%$ comparisons, a sample size of 64 in each group would have $80 \%$ power to detect, at a single time point, a mean difference of 0.5 unit, assuming that the common standard deviation was 1.0 for conjunctival redness using a two-group $t$-test with a $5 \%$ level of significance (two-sided). The probability of rejecting the null hypothesis for at least two of the three time points was $89.6 \%$ (assuming independence among the three time points).

\section{Results Study population}

A total of 202 patients were randomized in the study between December 2011 and March 2012; all were available for the safety analysis. Two patients discontinued after randomization but before the scheduled CAC; therefore, 200 patients were available for the intent-to-treat efficacy analysis.

Reasons for study discontinuation were similar across treatment groups, with 16 patients discontinuing the study early after visit $3 \mathrm{~A}$ (Figure 1). Patient demographic and baseline characteristics were similar across treatment groups, except that different proportions of participants were allergic to different types of allergens causing allergic conjunctivitis (Table 1).

\section{Efficacy analysis}

Olopatadine $0.77 \%$ was significantly better $(P<0.001)$ than vehicle in reducing ocular itching, as shown by the treatment difference in means at all three post-CAC time points $(3,5$, and 7 minutes) at onset of action and at 16- and 24-hour duration of action $(P<0.001$ for all, Figure 2A). Clinical relevance is considered by the FDA as a mean difference of 1 unit or greater from vehicle in a CAC study. The difference

Table I Demographic and baseline characteristics (intent-to-treat population) ${ }^{\mathrm{a}}$

\begin{tabular}{|c|c|c|c|}
\hline Characteristics & $\begin{array}{l}\text { Olopatadine } 0.77 \% \\
(n=66)\end{array}$ & $\begin{array}{l}\text { Olopatadine } 0.2 \% \\
(n=66)\end{array}$ & Vehicle $(n=68)$ \\
\hline \multicolumn{4}{|l|}{ Age, years } \\
\hline Mean (SD) & $40.9(13.1)$ & $40.7(14.2)$ & $41.8(13.3)$ \\
\hline Range & $18-68$ & $18-73$ & $19-77$ \\
\hline I8-64, n (\%) & $64(97.0)$ & $64(97.0)$ & $66(97.1)$ \\
\hline$\geq 65, \mathrm{n}(\%)$ & $2(3.0)$ & $2(3.0)$ & $2(2.9)$ \\
\hline \multicolumn{4}{|l|}{ Sex, n (\%) } \\
\hline Male & $23(34.8)$ & $24(36.4)$ & $29(42.6)$ \\
\hline Female & $43(65.2)$ & $42(63.6)$ & $39(57.4)$ \\
\hline \multicolumn{4}{|l|}{ Ethnicity, n (\%) } \\
\hline White & $50(75.8)$ & $52(78.8)$ & $57(83.8)$ \\
\hline Black or African-American & $14(2 \mid .2)$ & II (16.7) & $8(11.8)$ \\
\hline Asian & $\mathrm{I}(\mathrm{I} .5)$ & $\mathrm{I}(\mathrm{I} .5)$ & $\mathrm{I}(1.5)$ \\
\hline American Indian or Alaska Native & $\mathrm{I}(\mathrm{I} .5)$ & $\mathrm{I}(\mathrm{I} .5)$ & $\mathrm{I}(\mathrm{I} .5)$ \\
\hline Other & 0 & $\mathrm{I}(\mathrm{I} .5)$ & $\mathrm{I}(\mathrm{I} .5)$ \\
\hline \multicolumn{4}{|l|}{ Allergen type, n (\%) } \\
\hline Ragweed & $23(34.8)$ & $9(13.6)$ & $18(26.5)$ \\
\hline Grass & $17(25.8)$ & $22(33.3)$ & $23(33.8)$ \\
\hline Trees & $7(10.6)$ & $8(12.1)$ & $5(7.4)$ \\
\hline Dust mites & II (16.7) & $20(30.3)$ & II (I6.2) \\
\hline Cat dander & $7(10.6)$ & $6(9.1)$ & $10(14.7)$ \\
\hline Dog dander & I (I.5) & I (I.5) & I (I.5) \\
\hline
\end{tabular}

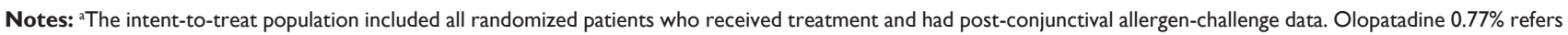
to olopatadine $\mathrm{HCl} 0.77 \%$ (equivalent to olopatadine $0.7 \%$ free base)-treatment group.

Abbreviation: SD, standard deviation. 
A

Olopatadine $0.77 \%$

versus

vehicle

Olopatadine $0.77 \%$ versus

olopatadine $0.2 \%$

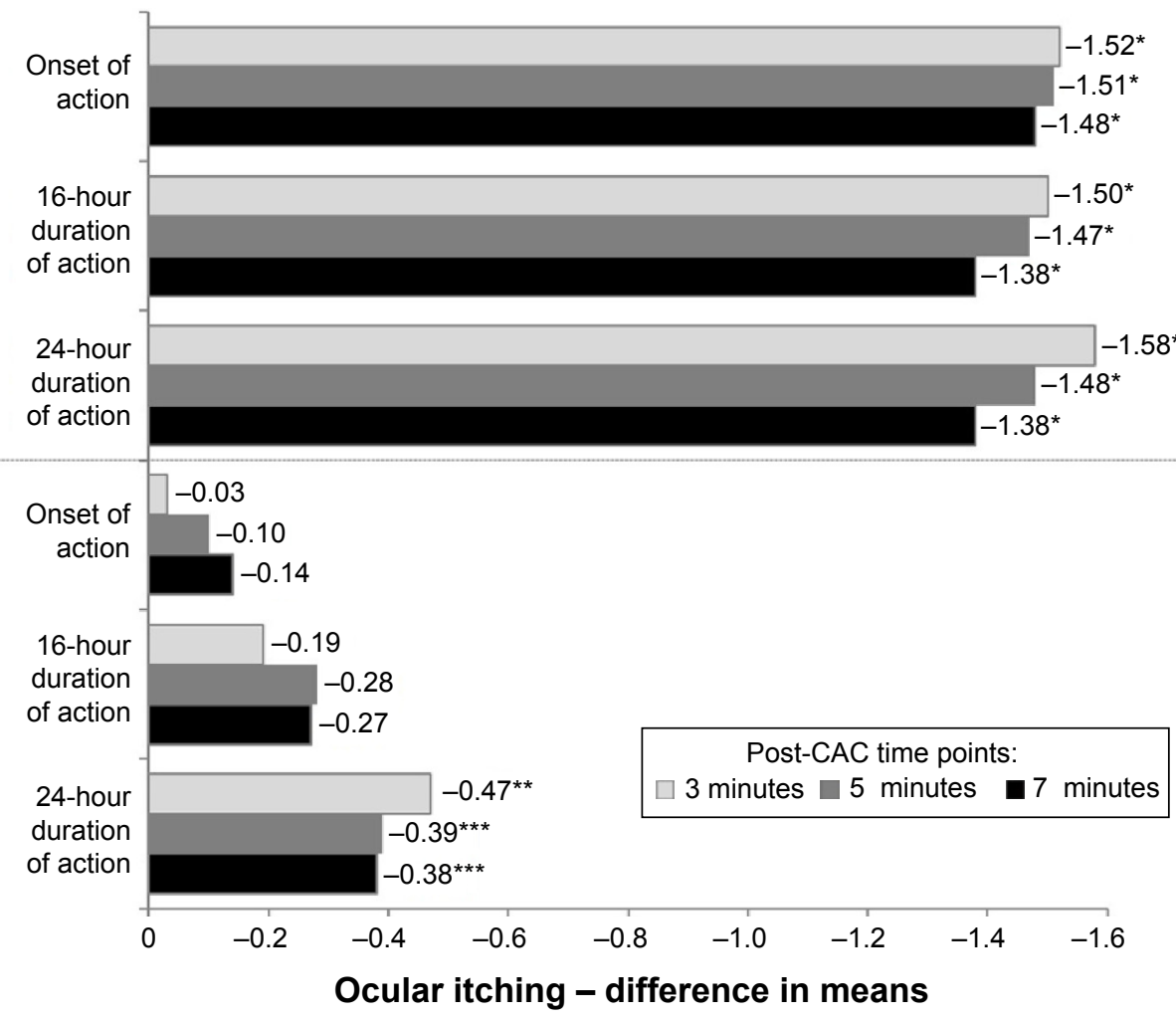

B

Olopatadine $0.77 \%$ versus vehicle

Olopatadine $0.77 \%$ versus olopatadine $0.2 \%$

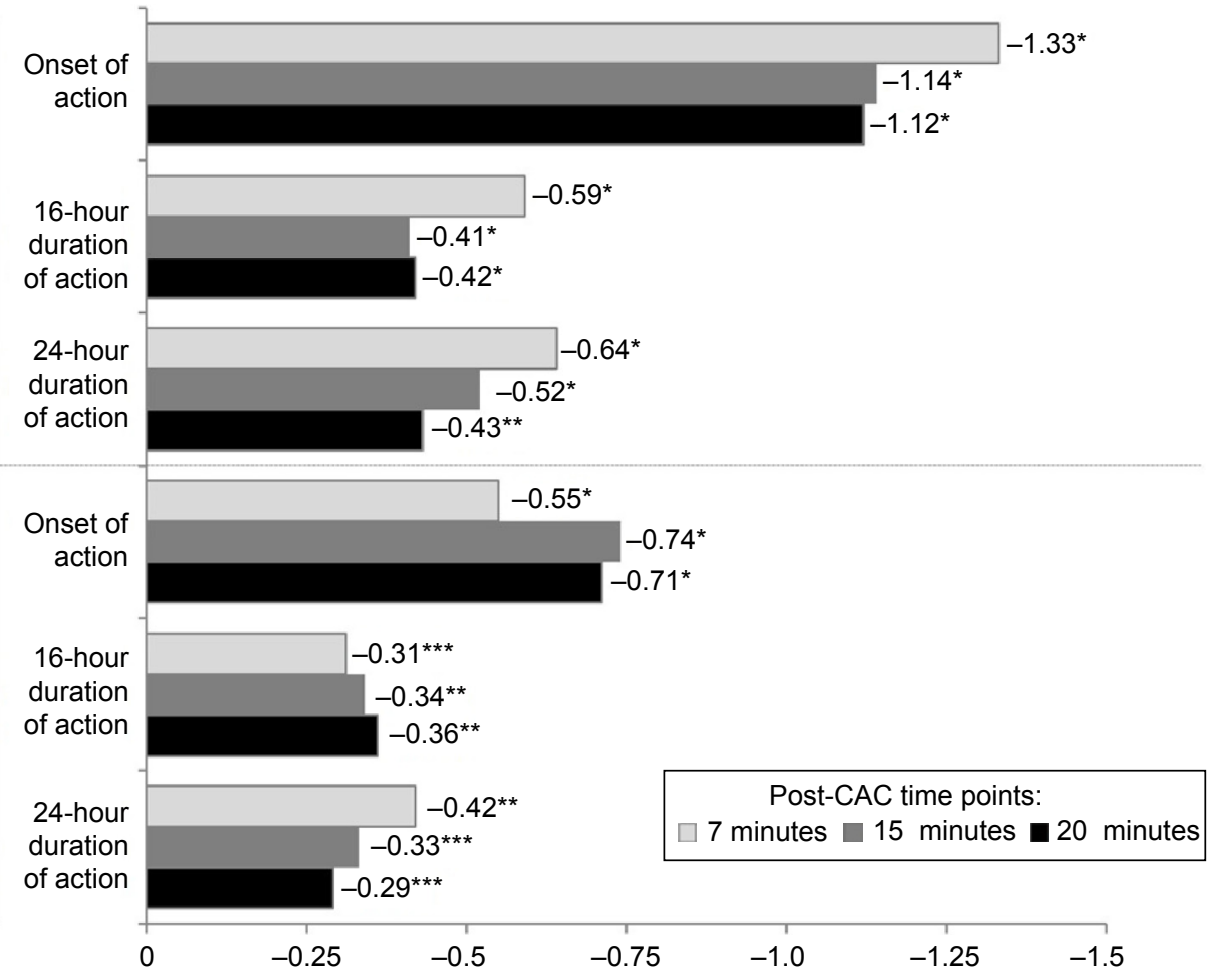

Conjunctival redness - difference in means

Figure 2 Treatment differences in means after conjunctival allergen-challenge (CAC): primary end points (intent-to-treat population).

Notes: $* P<0.001 ; * * P<0.01$; $* * * P<0.05$. Ocular itching $(\mathbf{A})$ examined at 3, 5, and 7 minutes, and conjunctival redness (B) examined at 7, 15 , and 20 minutes after $C A C$. Olopatadine $0.77 \%$ refers to olopatadine $\mathrm{HCl} 0.77 \%$ (equivalent to olopatadine $0.7 \%$ free base)-treatment group. 
in means was greater than 1 unit at all post-CAC time points for onset of action and 16- and 24-hour duration of action. Also, olopatadine $0.77 \%$ was superior to olopatadine $0.2 \%$ for ocular itching at all three post-CAC time points at 24 hours after dosing $(P<0.05)$. The treatment effect of olopatadine $0.77 \%$ in reducing ocular itching was maintained consistently from immediately after dosing through 24 hours after dosing.

For conjunctival redness, olopatadine $0.77 \%$ was significantly better versus vehicle at all three post-CAC time points at onset of action and at 16- and 24-hour assessments $(P<0.01$ for all, Figure 2B). The difference in means was greater than 1 unit at all post-CAC time points for onset of action, but was less than 1 unit at all post-CAC time points for 16- and 24-hour duration of action. Olopatadine $0.77 \%$ was also superior to olopatadine $0.2 \%$ at treating conjunctival redness at all three post-CAC time points at 24 hours after dosing $(P<0.05)$. Similar results were obtained for total redness $(P<0.05)$. Lower scores at all post-CAC time points at onset of action and 16- and 24-hour assessments were also seen with olopatadine $0.77 \%$ versus vehicle for ciliary, episcleral, and total redness.

A reduced mean score for chemosis was observed for olopatadine $0.77 \%$ compared with its vehicle and olopatadine $0.2 \%$ at 7,15 , and 20 minutes after $\mathrm{CAC}$ at onset of action, and at 16, and 24 hour assessments (Figure 3A). Similar results were obtained for tearing (Figure $3 \mathrm{~B}$ ).

\section{Safety analysis}

A total of 202 patients were exposed to the study medication for 3 nonconsecutive days, with one dose per visit over a 3-week period. Based on the review of incidence and individual characteristics (onset, intensity, duration, and outcome) of treatment-emergent AEs (Table 2), none of which were serious, no safety concerns were identified for olopatadine $0.77 \%$ or $0.2 \%$. Analysis of the safety parameters measured over the course of the study demonstrated no discernable trends or clinically relevant differences between the treatment groups.

\section{Discussion}

This double-masked, randomized, controlled trial assessed for the first time the efficacy and safety of once-daily olopatadine $0.77 \%$ compared with its vehicle and olopatadine $0.2 \%$ for the treatment of allergic conjunctivitis using a CAC model. We found that olopatadine $0.77 \%$ was superior to both its vehicle and olopatadine $0.2 \%$ for the treatment of allergic conjunctivitis.
The efficacy of olopatadine $0.77 \%$ versus vehicle and olopatadine $0.2 \%$ was evaluated immediately after dosing for onset of action and at 16 and 24 hours after dosing to assess the duration of action using the CAC model. This model is appropriate to test the efficacy of antiallergic agents, as it accurately replicates in a controlled and reproducible setting the true IgE-mediated allergic reaction seen in patients with allergic conjunctivitis. Indeed, the CAC model is a standardized testing model widely accepted by the FDA, as well as the Japanese Pharmaceuticals and Medical Devices Agency for registration purposes. ${ }^{31-33}$ In this study, patients with a history of allergic conjunctivitis were enrolled based on a sufficiently severe response to a controlled CAC on two separate occasions. One advantage of CAC studies over environmental studies is that participants reliably come into contact with the allergen that triggers their allergic conjunctivitis, whereas in environmental studies this is not necessarily the case, and interpretation of results may therefore be confounded. ${ }^{28,29}$ Other advantages of the CAC model include individual titration of allergens to obtain a threshold dose for adequate reactivity and the highly standardized grading systems used. $^{28}$

As previously mentioned, the ocular symptoms of rhinoconjunctivitis can affect the quality of life of patients. ${ }^{5}$ Olopatadine $0.77 \%$ fulfills the need for a treatment that provides full symptom relief over the duration of an entire 24-hour day. The present study has shown that olopatadine $0.77 \%$ is superior to its vehicle for the treatment of ocular itching at the onset of action (immediately after dosing), as well as having a lasting duration of action for 24 hours. Olopatadine $0.77 \%$ is also superior to its vehicle and olopatadine $0.2 \%$ for the treatment of conjunctival and total redness at onset of action and for up to 24 hours. These results showed that the relief from ocular itching provided by olopatadine $0.77 \%$ was highly consistent, and was maintained over 24 hours. Furthermore, olopatadine $0.77 \%$ showed reduced chemosis and tearing compared with its vehicle and olopatadine $0.2 \%$ at onset of action and for up to 24 hours. These findings are important, because allergen concentrations vary throughout the 24-hour day-night cycle, peaking at different times depending on the allergen and local environmental conditions.

Patients with difficulty managing their allergic conjunctivitis symptoms with one dose of their antiallergy ocular drops and consequently having to use a second dose may benefit from the increased convenience of a once-daily olopatadine $0.77 \%$ dosing regimen. Furthermore, once-daily regimens have been shown to contribute significantly to patient 
A

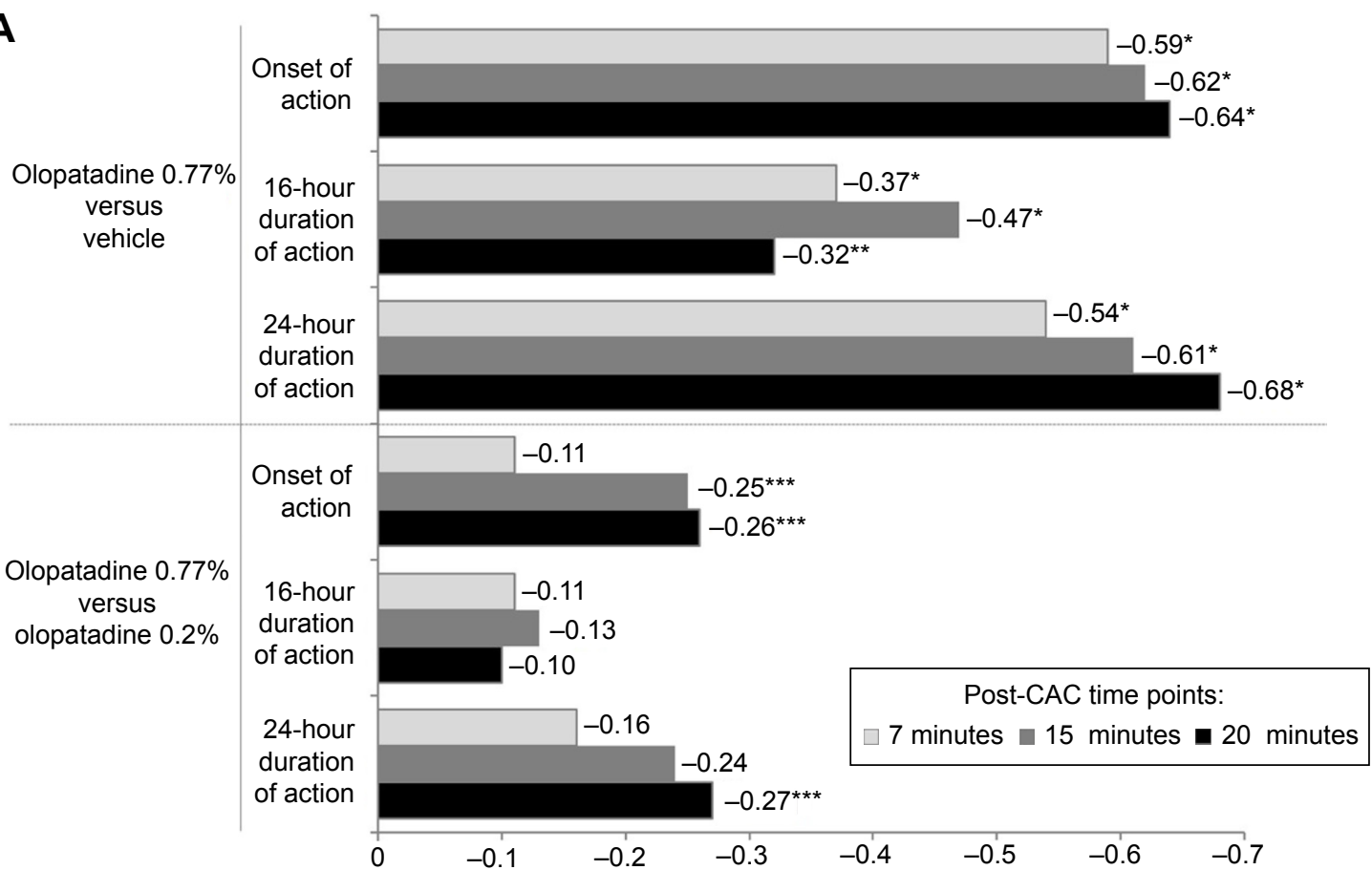

\section{Chemosis - difference in means}

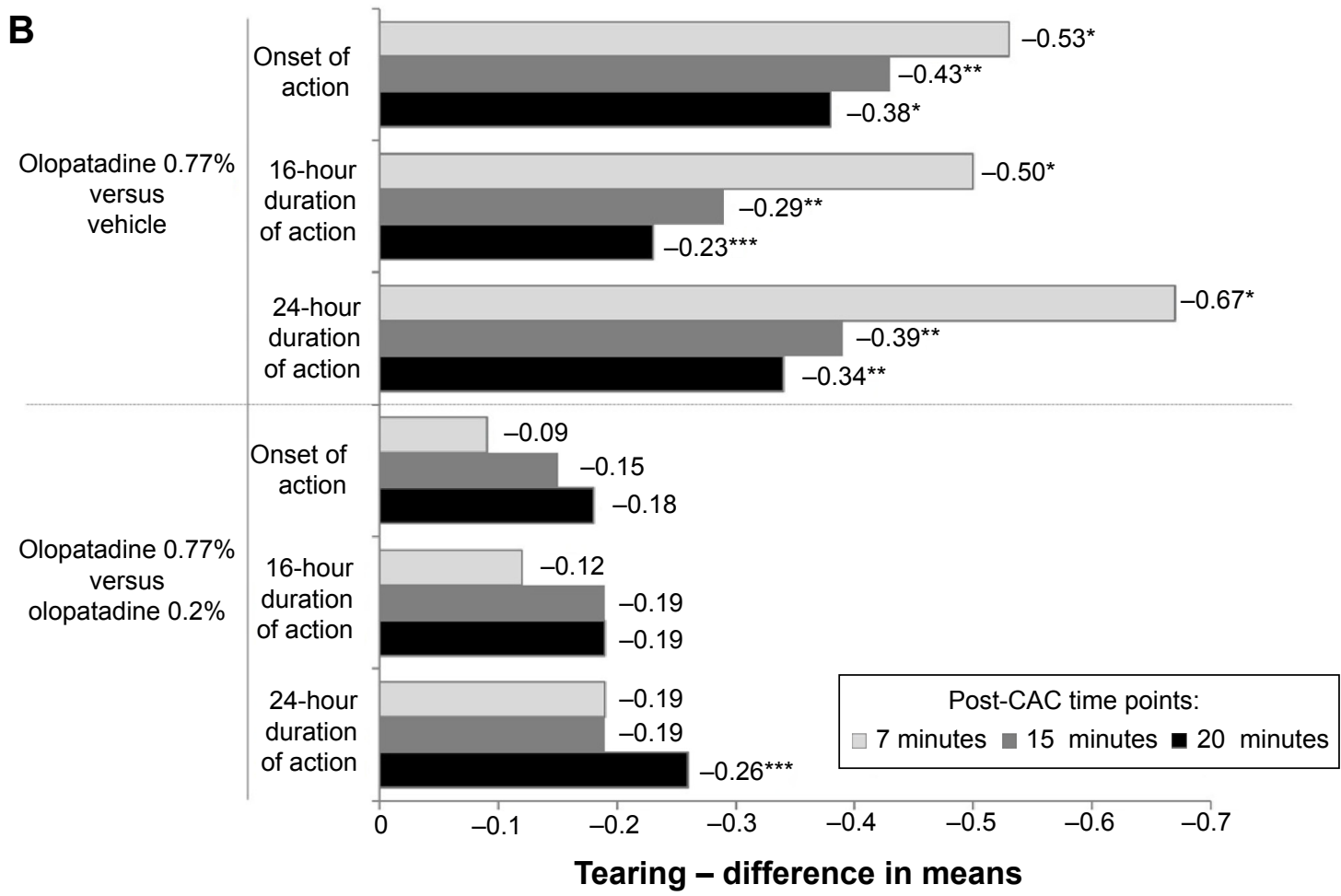

Figure 3 Treatment differences in means after conjunctival allergen-challenge (CAC): supportive end points (intent-to-treat population).

Notes: ${ }^{* P}<0.001$; ${ }^{*} \mathrm{P}<0.01$; ${ }^{* * *} \mathrm{P}<0.05$. Chemosis $(\mathbf{A})$ and tearing $(\mathbf{B})$ at $7, \mathrm{I}$, and 20 minutes after CAC. Olopatadine $0.77 \%$ refers to olopatadine $\mathrm{HCl} 0.77 \%$ (equivalent to olopatadine $0.7 \%$ free base)-treatment group.

compliance, ${ }^{34}$ reducing the risk of missed doses and possibly improving treatment outcomes and symptom control. ${ }^{35}$

Based on the review of AEs and ocular safety parameters, no safety concerns were identified for olopatadine $0.77 \%$ after once daily dosing for 3 nonconsecutive days in adults with allergic conjunctivitis. Evidence from previous studies demonstrates that olopatadine $0.2 \%$ is well tolerated in subjects with a history of allergic conjunctivitis. ${ }^{10,11,36}$ Olopatadine 
Table 2 Summary of treatment-emergent AEs (safety population)

\begin{tabular}{|c|c|c|c|}
\hline AE category, n (\%) & $\begin{array}{l}\text { Olopatadine } 0.77 \% \\
(n=66)\end{array}$ & $\begin{array}{l}\text { Olopatadine } 0.2 \% \\
(n=68)\end{array}$ & Vehicle $(n=68)$ \\
\hline Discontinued because of $\mathrm{AE}$ & $2(3.0)$ & 0 & $\mathrm{I}(\mathrm{I} .5)$ \\
\hline Treatment-related & 0 & 0 & 0 \\
\hline Not treatment-related & $2(3.0)$ & 0 & $\mathrm{I}(\mathrm{l} .5)$ \\
\hline Patients with one or more treatment-emergent & $6(9.1)$ & $5(7.4)$ & $5(7.4)$ \\
\hline \multicolumn{4}{|l|}{$A E$} \\
\hline Patients with one or more treatment-emergent & $\mathrm{I}(\mathrm{I} .5)$ & 0 & $\mathrm{I}(\mathrm{l} .5)$ \\
\hline \multicolumn{4}{|l|}{$\mathrm{AE}$ related to treatment } \\
\hline \multicolumn{4}{|l|}{ Treatment-related AEs } \\
\hline Vision blurred & 0 & 0 & $\mathrm{I}(\mathrm{I} .5)$ \\
\hline Headache & $\mathrm{I}(\mathrm{l} .5)$ & 0 & 0 \\
\hline
\end{tabular}

Note: Olopatadine $0.77 \%$ refers to olopatadine $\mathrm{HCl} 0.77 \%$ (equivalent to olopatadine $0.7 \%$ free base)-treatment group. Abbreviation: $\mathrm{AE}$, adverse event.

$0.2 \%$ administered once daily for 6 weeks was also shown to be safe and well tolerated in children who were $\geq 3$ years old. ${ }^{18}$ This study showed that the safety profile of olopatadine $0.77 \%$ is comparable with that of its vehicle, as well as olopatadine $0.2 \%$. An additional study has been conducted to assess the safety of olopatadine $0.77 \%$, which included pediatric and adolescent patients (ClinicalTrials. gov identifier NCT01698814), and has shown that 6 weeks of daily treatment with olopatadine $0.77 \%$ reveals a safety profile comparable to its vehicle. The safety profile is also consistent with that of olopatadine $0.2 \%$, as previously established.

As with all clinical trials, this study has some limitations. A drawback of the CAC model as implemented in this study was that neither the late-phase response nor quality-of-life outcomes were tested. Additional studies using a modified version of the CAC model could assess efficacy of treatment against a late-phase response. Also, slightly more patients reactive to seasonal allergens (ragweed, grass, and trees) than to perennial allergens (dust mite, cat dander, and dog dander) were observed in the olopatadine $0.77 \%$-treatment group than the olopatadine $0.2 \%$ or vehicle groups. However, each randomized patient had to meet a positive bilateral CAC response at screening visits 1 and 2, as described in the "Patients and methods" section, in order to be eligible for the study. Therefore, regardless of the specific type of allergen, all randomized patients met the minimum itching and redness criteria and were randomized to study treatment at visit $3 \mathrm{~A}$ only after all entry criteria were met. Therefore, this slight difference in distribution of seasonal and perennial allergens was not considered significant in affecting the outcome of the study.

In conclusion, olopatadine $0.77 \%$ is superior to both its vehicle and olopatadine $0.2 \%$ for the treatment of allergen-mediated ocular itching and conjunctival redness. The relief from ocular itching provided by olopatadine $0.77 \%$ is maintained throughout a period of 24 hours, as assessed by the CAC model, supporting once-daily dosing of olopatadine $0.77 \%$ in the treatment of ocular itching associated with allergic conjunctivitis. This study showed that the benefit-risk profile for olopatadine $0.77 \%$ is superior to olopatadine $0.2 \%$ for the treatment of allergic conjunctivitis-associated ocular itching when both are dosed once daily.

\section{Author contributions}

All authors actively contributed to the development of this article through participation in the research and preparation of the manuscript. Also, all authors reviewed and approved the final version. AN had full access to all the data in the study, and takes responsibility for the integrity of the data and the accuracy of the data analysis.

\section{Acknowledgments}

Alcon Research Ltd (Fort Worth, TX) participated in the design of the study, analysis of the data, and approval of the manuscript. Adeniyi Adewale, of Alcon Research, confirmed the accuracy of the data and data analysis. In addition, Ora Inc provided support with the design and conduct of the study. This study was sponsored by Alcon Research. Medical writing support, which was funded by Alcon Research, was provided by Silvia Grisendi, of DJE Science. A subset of the results of this paper were presented at the American Academy of Allergy, Asthma \& Immunology Meeting 2014 in San Diego, CA, as a poster presentation with interim findings. The poster's abstract was published as an online supplement to the Journal of Allergy and Clinical Immunology, and can be accessed on the journal's 
website - http://www.jacionline.org. The actual paper, however, has never been published.

\section{Disclosure}

GT (study investigator) received consultancy fees from Ora Inc and reimbursement of traveling expenses from Alcon Research. AN (clinical trial manager) is an employee of Alcon Research. MB (study investigator) reports no conflicts of interest in this work. The authors report no other conflicts of interest in this work.

\section{References}

1. Katelaris $\mathrm{CH}$, Bielory L. Evidence-based study design in ocular allergy trials. Curr Opin Allergy Clin Immunol. 2008;8(5):484-488.

2. del Cuvillo A, Sastre J, Montoro J, et al. Allergic conjunctivitis and H1 antihistamines. J Investig Allergol Clin Immunol. 2009;19 Suppl 1:11-18.

3. Johansson SG, Bieber T, Dahl R, et al. Revised nomenclature for allergy for global use: Report of the Nomenclature Review Committee of the World Allergy Organization, October 2003. J Allergy Clin Immunol. 2004; 113(5):832-836.

4. Chigbu DI. The management of allergic eye diseases in primary eye care. Cont Lens Anterior Eye. 2009;32(6):260-272.

5. Virchow JC, Kay S, Demoly P, Mullol J, Canonica W, Higgins V. Impact of ocular symptoms on quality of life (QoL), work productivity and resource utilisation in allergic rhinitis patients - an observational, cross sectional study in four countries in Europe. J Med Econ. 2011;14(3):305-314.

6. Blaiss MS. Allergic rhinoconjunctivitis: burden of disease. Allergy Asthma Proc. 2007;28(4):393-397.

7. Uchio E. Treatment of allergic conjunctivitis with olopatadine hydrochloride eye drops. Clin Ophthalmol. 2008;2(3):525-531.

8. Azari AA, Barney NP. Conjunctivitis: a systematic review of diagnosis and treatment. JAMA. 2013;310(16):1721-1729.

9. Yanni JM, Weimer LK, Sharif NA, Xu SX, Gamache DA, Spellman JM. Inhibition of histamine-induced human conjunctival epithelial cell responses by ocular allergy drugs. Arch Ophthalmol. 1999;117(5): 643-647.

10. Abelson MB, Gomes PJ, Vogelson CT, et al. Clinical efficacy of olopatadine hydrochloride ophthalmic solution $0.2 \%$ compared with placebo in patients with allergic conjunctivitis or rhinoconjunctivitis: a randomized, double-masked environmental study. Clin Ther. 2004;26(8):1237-1248.

11. Abelson MB, Spangler DL, Epstein AB, Mah FS, Crampton HJ. Efficacy of once-daily olopatadine $0.2 \%$ ophthalmic solution compared to twice-daily olopatadine $0.1 \%$ ophthalmic solution for the treatment of ocular itching induced by conjunctival allergen challenge. Curr Eye Res. 2007;32(12):1017-1022.

12. Aguilar AJ. Comparative study of clinical efficacy and tolerance in seasonal allergic conjunctivitis management with $0.1 \%$ olopatadine hydrochloride versus $0.05 \%$ ketotifen fumarate. Acta Ophthalmol Scand Suppl. 2000(230):52-55.

13. Artal MN, Luna JD, Discepola M. A forced choice comfort study of olopatadine hydrochloride $0.1 \%$ versus ketotifen fumarate $0.05 \%$. Acta Ophthalmol Scand Suppl. 2000(230):64-65.

14. Berdy GJ, Spangler DL, Bensch G, Berdy SS, Brusatti RC. A comparison of the relative efficacy and clinical performance of olopatadine hydrochloride $0.1 \%$ ophthalmic solution and ketotifen fumarate $0.025 \%$ ophthalmic solution in the conjunctival antigen challenge model. Clin Ther. 2000;22(7):826-833.

15. Brockman HL, Momsen MM, Knudtson JR, Miller ST, Graff G, Yanni JM. Interactions of olopatadine and selected antihistamines with model and natural membranes. Ocul Immunol Inflamm. 2003;11(4):247-268.
16. Katelaris CH, Ciprandi G, Missotten L, Turner FD, Bertin D, Berdeaux G. A comparison of the efficacy and tolerability of olopatadine hydrochloride $0.1 \%$ ophthalmic solution and cromolyn sodium $2 \%$ ophthalmic solution in seasonal allergic conjunctivitis. Clin Ther. 2002;24(10): $1561-1575$

17. Lanier BQ, Finegold I, D'Arienzo P, Granet D, Epstein AB, Ledgerwood GL. Clinical efficacy of olopatadine vs epinastine ophthalmic solution in the conjunctival allergen challenge model. Curr Med Res Opin. 2004;20(8):1227-1233.

18. Lichtenstein SJ, Pasquine TA, Edwards MR, Wells DT, Gross RD, Robertson SM. Safety and tolerability of olopatadine $0.2 \%$ in children and adolescents. J Ocul Pharmacol Ther. 2007;23(4):366-371.

19. Mah FS, Rosenwasser LJ, Townsend WD, Greiner JV, Bensch G. Efficacy and comfort of olopatadine $0.2 \%$ versus epinastine $0.05 \%$ ophthalmic solution for treating itching and redness induced by conjunctival allergen challenge. Curr Med Res Opin. 2007;23(6):1445-1452.

20. Ohno S. [A multicenter, double-masked, randomized evaluation of olopatadine $0.2 \%$ using the conjunctival allergen challenge model in Japanese patients with allergic conjunctivitis]. Nihon Ganka Gakkai Zasshi. 2012;116(12):1123-1129. Japanese.

21. Ohno S, Ando M. [A 10-week safety and efficacy evaluation of olopatadine, $0.2 \%$ instilled twice-daily in patients with allergic conjunctivitis in Japan]. Nihon Ganka Gakkai Zasshi. 2012;116(9):869-879. Japanese.

22. Rosenwasser LJ, Mahr T, Abelson MB, Gomes PJ, Kennedy K. A comparison of olopatadine $0.2 \%$ ophthalmic solution versus fluticasone furoate nasal spray for the treatment of allergic conjunctivitis. Allergy Asthma Proc. 2008;29(6):644-653.

23. Scoper SV, Berdy GJ, Lichtenstein SJ, et al. Perception and quality of life associated with the use of olopatadine $0.2 \%$ (Pataday) in patients with active allergic conjunctivitis. Adv Ther. 2007;24(6):1221-1232.

24. Spangler DL, Bensch G, Berdy GJ. Evaluation of the efficacy of olopatadine hydrochloride $0.1 \%$ ophthalmic solution and azelastine hydrochloride $0.05 \%$ ophthalmic solution in the conjunctival allergen challenge model. Clin Ther. 2001;23(8):1272-1280.

25. Vogelson CT, Abelson MB, Pasquine T, et al. Preclinical and clinical antiallergic effect of olopatadine $0.2 \%$ solution 24 hours after topical ocular administration. Allergy Asthma Proc. 2004;25(1):69-75.

26. Yaylali V, Demirlenk I, Tatlipinar S, et al. Comparative study of $0.1 \%$ olopatadine hydrochloride and $0.5 \%$ ketorolac tromethamine in the treatment of seasonal allergic conjunctivitis. Acta Ophthalmol Scand. 2003;81(4):378-382.

27. Gamache DA, Alani L, Ghosh M, Galán FJ, Perdiguer N, Singh O, inventors; Alcon Research Ltd, assignee. High concentration olopatadine ophthalmic composition. World Intellectual Property Organization patent WO2012159064 2012 Nov 22.

28. Abelson MB, Loeffler O. Conjunctival allergen challenge: models in the investigation of ocular allergy. Curr Allergy Asthma Rep. 2003;3(4): 363-368.

29. Abelson MB, Chambers WA, Smith LM. Conjunctival allergen challenge. A clinical approach to studying allergic conjunctivitis. Arch Ophthalmol. 1990;108(1):84-88.

30. World Medical Association. World Medical Association Declaration of Helsinki: ethical principles for medical research involving human subjects. JAMA. 2013;310(20):2191-2194.

31. US Food and Drug Administration. Dermatologic and Ophthalmic Drugs Advisory Committee meeting briefing document: Bepreve ${ }^{\mathrm{TM}}$ (bepotastine besilate ophthalmic solution) 1.5\%. 2009. Available from: http://www.fda.gov/downloads/AdvisoryCommittees/CommitteesMeetingMaterials/Drugs/DermatologicandOphthalmicDrugsAdvisoryCommittee/UCM170900.pdf. Accessed May 13, 2015.

32. US Food and Drug Administration. Statistical review and evaluation: alcaftadine ophthalmic solution $0.25 \%$. 2009. Available from: http:// www.fda.gov/downloads/drugs/developmentapprovalprocess/developmentresources/ucm223818.pdf. Accessed May 13, 2015. 
33. US Food and Drug Administration. Clinical review of NDA 206276. 2014. Available from: http://www.fda.gov/downloads/drugs/developmentapprovalprocess/developmentresources/ucm434580.pdf. Accessed May 13, 2015.

34. Claxton AJ, Cramer J, Pierce C. A systematic review of the associations between dose regimens and medication compliance. Clin Ther. 2001;23(8):1296-1310.
35. Richter A, Anton SE, Koch P, Dennett SL. The impact of reducing dose frequency on health outcomes. Clin Ther. 2003;25(8):2307-2335.

36. Abelson MB, Gomes PJ, Pasquine T, Edwards MR, Gross RD, Robertson SM. Efficacy of olopatadine ophthalmic solution $0.2 \%$ in reducing signs and symptoms of allergic conjunctivitis. Allergy Asthma Proc. 2007;28(4):427-433.

\section{Publish your work in this journal}

Clinical Ophthalmology is an international, peer-reviewed journal covering all subspecialties within ophthalmology. Key topics include: Optometry; Visual science; Pharmacology and drug therapy in eye diseases; Basic Sciences; Primary and Secondary eye care; Patient Safety and Quality of Care Improvements. This journal is indexed on

Submit your manuscript here: http://www.dovepress.com/clinical-ophthalmology-journal

\section{Dovepress}

PubMed Central and CAS, and is the official journal of The Society of Clinical Ophthalmology (SCO). The manuscript management system is completely online and includes a very quick and fair peer-review system, which is all easy to use. Visit http://www.dovepress.com/ testimonials.php to read real quotes from published authors. 